\title{
Design and Development of Novel Dual-Compartment Capsule for Improved Gastroretention
}

\author{
Ganesh B. Patil, Saurabh S. Singh, Ketan P. Ramani, \\ Vivekanand K. Chatap, and Prashant K. Deshmukh
}

Post-Graduate Department of Pharmaceutics, H R Patel Institute of Pharmaceutical Education and Research, Karvand Naka, Dhule District, Shirpur, Maharashtra 425 405, India

Correspondence should be addressed to Prashant K. Deshmukh; pkdesh@rediffmail.com

Received 30 October 2012; Accepted 11 December 2012

Academic Editors: A. N. Assimopoulou, A. Ghosal, S. Mutalik, and E. Pina

Copyright (c) 2013 Ganesh B. Patil et al. This is an open access article distributed under the Creative Commons Attribution License, which permits unrestricted use, distribution, and reproduction in any medium, provided the original work is properly cited.

\begin{abstract}
The aim of the proposed research work was to develop a novel dual-compartment capsule (NDCC) with polymeric disc for gastroretentive dosage form, which will ultimately result in better solubility and bioavailability of Ofloxacin. Floating ring caps were formulated by using different natural polymers, separating ring band and swellable polymer located at the bottom of capsule. Formulated ring caps were assessed for coating thickness, In vitro buoyancy, In vitro drug release, release kinetics and stability studies. Coating attained by the capsule shell was found to be $0.0643 \mathrm{~mm}$. Depending on nature of natural polymer used, most of the formulations showed buoyancy for more than $9 \mathrm{hrs}$. Developed formulation demonstrated considerably higher drug release up to $9 \mathrm{hrs}$. The developed formulation $\mathrm{F}_{\mathrm{E} 2}$ depicted the drug release according to Korsmeyer-Peppas model. There was not any significant change in performance characteristics of developed ring caps after subjecting them to stability studies. The present study suggests that the use of NDCC for oral delivery of Ofloxacin could be an alternative to improve its systemic availability which could be regulated by the floating approach. The designed dosage system can have futuristic applications over payloads which require stomach-specific delivery.
\end{abstract}

\section{Introduction}

Although tremendous advances have been made in drug delivery, considering costs and patient compliance, the oral route still remains the preferred route of administration for therapeutic agents. The environment of gastrointestinal tract significantly varies from stomach to large intestine (Table 1) [1]. This variation could serve a promising platform for the site-specific drug delivery of therapeutics.

The presence of a dosage form in the upper part of the gastrointestinal tract is important especially for drugs that are degraded or metabolized in the intestine or for drugs with local activity in the stomach $[2,3]$. Likewise Singh and Kim [4] suggested that floating drug delivery is of particular interest for drugs which (a) have local action in the stomach, (b) are primarily absorbed in the stomach, (c) have poor solubility at an alkaline $\mathrm{pH}$, (d) have a narrow window of absorption, and (e) are unstable in the intestinal or colonic environment. Gastrointestinal retention depends on many factors such as density and size of the dosage form, the fasting or fed condition of the patient, and the nature of the meal as well as posture [5-7]. Several gastroretentive formulation approaches such as high density [8], swelling [9], bioadhesive [10], magnetic [11], and floating [12] systems have been developed for enhanced gastroretention.

Local action in stomach is often used for curing gastric infection and better bioavailability of drugs which shows $\mathrm{pH}$-dependent solubility. Ofloxacin is known to have $\mathrm{pH}$ dependant solubility; it is more soluble in acidic $\mathrm{pH}$ and slightly soluble at neutral or alkaline $\mathrm{pH}$ conditions [13].

In the present investigation, for better solubility and bioavailability of ofloxacin an attempt was made to develop (gastroretentive drug delivery system) (GRDS) of ofloxacin by fabricating it in form of novel dual-compartment capsule (NDCC) for gastroretentive dosage form. The present study also reveals the effects of different polymers with varying concentration on drug release and floating property of prepared formulation. 
TABLE 1: Salient features of GI tract.

\begin{tabular}{lcc}
\hline Segment & Surface area & $\mathrm{pH}$ \\
\hline Stomach & $3.5 \mathrm{~m}^{2}$ & $1-3.5$ \\
Duodenum & $2 \mathrm{~m}^{2}$ & $4-6.5$ \\
Jejunum & $180 \mathrm{~m}^{2}$ & $5-7$ \\
Ileum & $280 \mathrm{~m}^{2}$ & $6-8$ \\
Colon & $1-3 \mathrm{~m}^{2}$ & $6-8$ \\
\hline
\end{tabular}

The objective of the current investigation was to develop a novel dual-compartment capsule (NDCC) with polymeric disc for gastroretentive dosage form. The study was inspired from patented RingCap technology for enhanced drug release by augmentation of surface area approach and OROS pushpull osmotic system.

\section{Materials and Methods}

2.1. Materials. Ofloxacin was generously gifted by Ajanta Pharma, Mumbai, India. Carbopol 934P, Carbopol 940P, HPMC A15, HPMC E15, and HPMC K15 were procured from HI-MEDIA, Eudragit S100 was purchased from Loba Chemie, Mumbai, and Xanthan gum, Guar gum, Sodium Alginate, and Glycerol were procured from Merck Mumbai, India. All other chemicals and reagents used were of analytical grade.

2.2. Solubility of Ofloxacin in Different $p H$ Conditions. In concordance with Chavanpatil et al. the study was conducted to depict the solubility of ofloxacin at varying $\mathrm{pH}$ conditions. Saturated solutions of ofloxacin were prepared by dispersing an excess amount of drug in the buffer with $\mathrm{pH} 1,1.2,3$, $4.5,5.8,6.8,7.2$, and 7.5. The samples were subjected to orbital shaker (Remi Instrument Ltd. CIS-24) for 72 hours to aid maximum dissolution of the drug. After the incubation period, clear saturated solutions were obtained by filtration ( $0.45 \mu \mathrm{m}$ Millipore filter paper), and the concentration of the drug was determined spectrophotometrically (UV-1800 PC Shimadzu, Japan) at the wavelength of $291 \mathrm{~nm}$, after the appropriate dilution in the corresponding $\mathrm{pH}$ buffer. All solubilities were measured in triplicate at room temperature [14].

2.3. Preparation of Separating Polymeric Disc. It was prepared by making 4\% HMPC K15 solution in water, followed by the addition of $5 \%$ glycerol which was preoptimized. Then the mixture was poured to petridish and was allowed to dry at $45^{\circ} \mathrm{C}$ for 12 hours. The dried film was cut uniformly to obtain circular discs with punch to have $1 \mathrm{~mm}$ thickness and diameter of $5.1 \mathrm{~mm}$.

2.4. Preparation of Enteric Coated Gelatin Body. Enteric coated gelatin bodies were coated in a coating pan rotated at $50 \mathrm{rpm}$ by spraying with a $10 \%$ solution of Eudragit S100 in acetone to get uniform coating over the surface of gelatin body. As Eudragit S100 is insoluble in gastric environment and buffer solutions with $\mathrm{pH}$ below 6 , thus it provides protection to the prepared formulation $[15,16]$.

2.5. Fabrication of NDCC. In enteric coated gelatin body, initially $50 \mathrm{mg}$ Carbopol 934P was placed at the base; over this circular separating polymeric disc of $1 \mathrm{~mm}$ thickness it was placed.

As shown in Table 2, prepared polymeric mixture of ofloxacin in combination with different polymers was placed over this barrier disc. Thereafter uncoated gelatin cap was joined over the enteric body of capsule to complete the design of NDCC. The polymers used with model drug are swellable and show hydration when they come in contact with acidic media of stomach. As the enteric gelatin body remains intact in acidic environment, it protects the formulation and allows the exposure only from open face. The disc pushes the drug polymeric mixture due to the swelling of Carbopol 934P on hydration which is located deep at the base. When the prepared capsule was assessed in vitro in simulated gastric fluid, it was observed that the cap quickly gets dissolved, but the enteric body still remains intact. Air trapped inside the intact capsule shell offers the buoyancy.

2.6. Evaluation of Coating Thickness. The prepared enteric coated capsules were evaluated for the thickness attained by Eudragit S100 coating. The thickness was measured by Digimatic caliper (Mitutoyo Corporation, Japan). Initially, the bare capsule shells were subjected for thickness measurement at three different positions. This was followed by final measurement at three different positions of the coated capsules. The changes in thickness indicate the final Eudragit coating acquired by the capsules. The evaluation was done in triplicate:

$$
\begin{array}{r}
\text { Coating thickness }=\text { Thickness of coated capsule } \\
- \text { Thickness of bare capsule. }
\end{array}
$$

2.7. Preparation of Novel Floating Capsules. Enteric gelatin bodies were filled with $50 \mathrm{mg}$ powder Carbopol $934 \mathrm{P}$ at the bottom on which a separating polymeric disc was placed. The polymeric mixture of ofloxacin (Table 1) was filled over it with light compression, and finally the capsule body was sealed with hard gelatin cap. Figure 1 demonstrates the fabrication and drug release from prepared capsule.

2.8. In Vitro Buoyancy Studies. The in vitro buoyancy was determined by the floating time and was studied here by two methods. Firstly, by placing the formulated capsule in a beaker containing $100 \mathrm{~mL}$ of $\mathrm{pH} 1.2 \mathrm{HCl}$. The floating duration of all capsules was determined by visual observation (Figure 3). Secondly, the duration of buoyancy was determined in the USP dissolution Apparatus II in an acid environment. The time interval between the introduction of the capsule into the dissolution medium and its buoyancy to the top of dissolution medium was taken as the duration of buoyancy observed visually [17]. 
TABLE 2: Composition of formulations.

\begin{tabular}{|c|c|c|c|c|c|c|c|c|c|c|c|c|}
\hline \multirow[b]{2}{*}{ Ingredients } & \multicolumn{12}{|c|}{ Formulation codes } \\
\hline & $\mathrm{F}_{\mathrm{A} 1}$ & $\mathrm{~F}_{\mathrm{A} 2}$ & $\mathrm{~F}_{\mathrm{E} 1}$ & $\mathrm{~F}_{\mathrm{E} 2}$ & $\mathrm{~F}_{\mathrm{K} 1}$ & $\begin{array}{c}\mathrm{F}_{\mathrm{K} 2} \\
\text { Quant }\end{array}$ & $\begin{array}{l}\mathrm{F}_{\mathrm{Cl}} \\
\text { in } \mathrm{m}\end{array}$ & $\mathrm{F}_{\mathrm{C} 2}$ & $\mathrm{~F}_{\mathrm{G} 1}$ & $\mathrm{~F}_{\mathrm{G} 2}$ & $\mathrm{~F}_{\mathrm{X} 1}$ & $\mathrm{~F}_{\mathrm{X} 2}$ \\
\hline Ofloxacin & 200 & 200 & 200 & 200 & 200 & 200 & 200 & 200 & 200 & 200 & 200 & 200 \\
\hline HPMC A15 & 60 & 40 & & & & & & & & & & \\
\hline HPMC E15 & & & 60 & 40 & & & & & & & & \\
\hline HPMC K15 & & & & & 60 & 40 & & & & & & \\
\hline Carbopol 940P & & & & & & & 60 & 40 & & & & \\
\hline Guar gum & & & & & & & & & 60 & 40 & & \\
\hline Xanthan gum & & & & & & & & & & & 60 & 40 \\
\hline Carbopol 934P & 50 & 50 & 50 & 50 & 50 & 50 & 50 & 50 & 50 & 50 & 50 & 50 \\
\hline
\end{tabular}

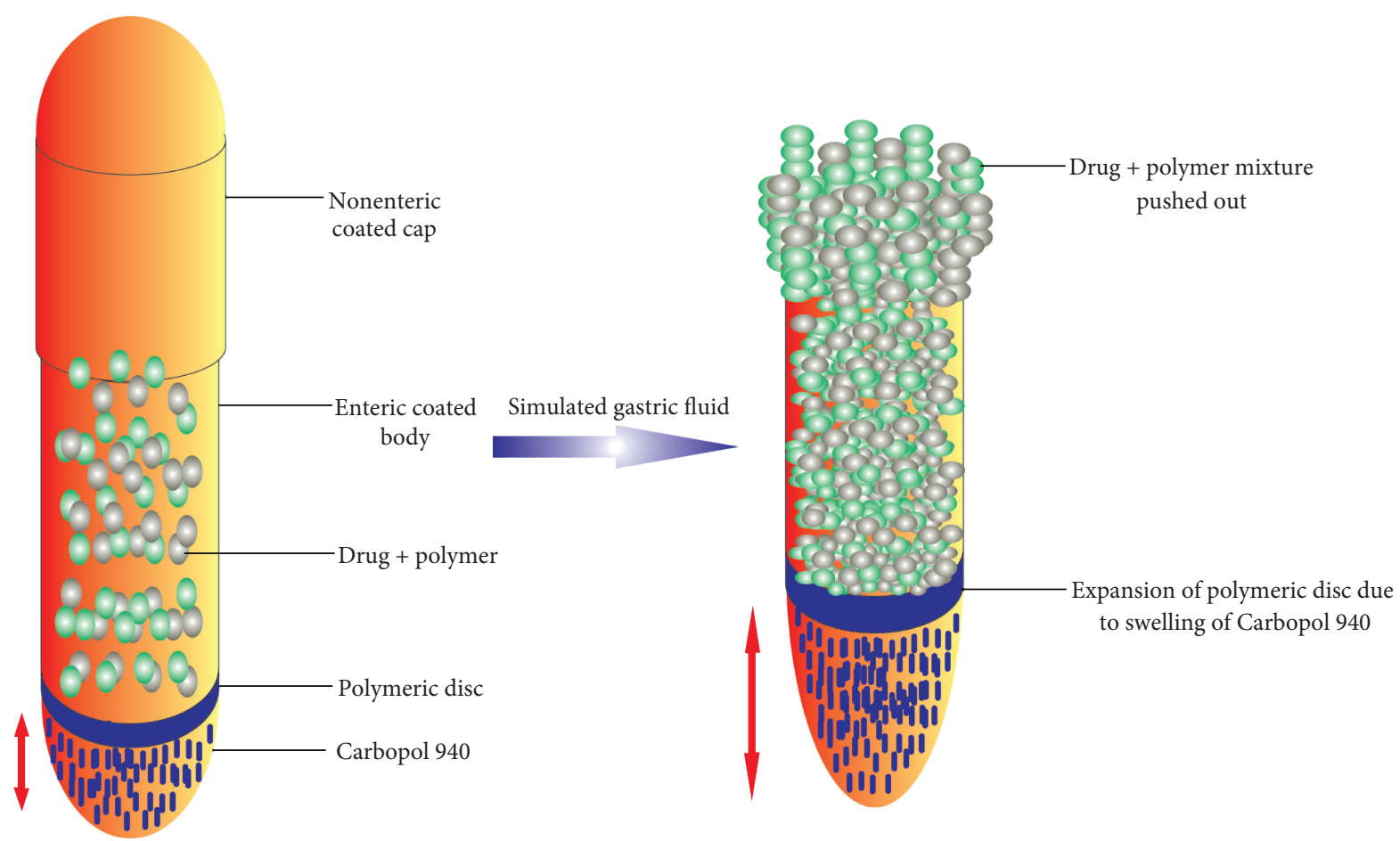

FIGURE 1: Schematic representation of drug release from novel dual compartment capsule.

2.9. In Vitro Drug Release. The release of ofloxacin from the capsules was studied using USP type II (paddle) dissolution apparatus (EDT-08Lx, Electrolab, India). The dissolution media included $900 \mathrm{~mL}$ of phosphate buffer $\mathrm{pH} 1.2$ (without pepsin) for entire study. The temperature was maintained at $37 \pm 0.5^{\circ} \mathrm{C}$ with paddle rotation speed of $50 \mathrm{rpm}$. Five milliliters of aliquot were withdrawn at predetermined time intervals of $0.5,1,2,3,4,5,6,7,8$, and 9 hours and filtered. The medium was replenished with $5 \mathrm{~mL}$ of fresh buffer each time. Sample was analyzed by using UV spectrophotometer (UV-1800 PC) at the wavelength of $291 \mathrm{~nm}$. The studies were performed in triplicate.

2.10. Stability Study. To assess the drug and formulation stability, stability studies were carried out according to $\mathrm{ICH}$ guidelines [18]. The drug polymer mixtures were filled in hard gelatin capsule size 00 and stored in air tight glass container. Samples were placed in stability chamber (Remi Programmable Environmental Test Chamber, India) under accelerated storage conditions $\left(45 \pm 2{ }^{\circ} \mathrm{C}, 75 \pm 5 \% \mathrm{RH}\right)$ for 3 months. At the end of studies, samples were evaluated for appearance, in vitro drug release, and infrared spectroscopy (Shimadzu FT-IR Affinity 1700).

\section{Results}

3.1. Solubility of Ofloxacin at Different $p H$ Range at Room Temperature. Solubility of Ofloxacin substantively decreased with an increase in a $\mathrm{pH}$ of media (Figure 2). It was found to be much higher in acidic $\mathrm{pH}$ compared to neutral and alkaline one. The solubility was found to be $41.2 \mathrm{mg} / \mathrm{mL}, 38.42 \mathrm{mg} / \mathrm{mL}, 29.57 \mathrm{mg} / \mathrm{mL}, 4.53 \mathrm{mg} / \mathrm{mL}$, 


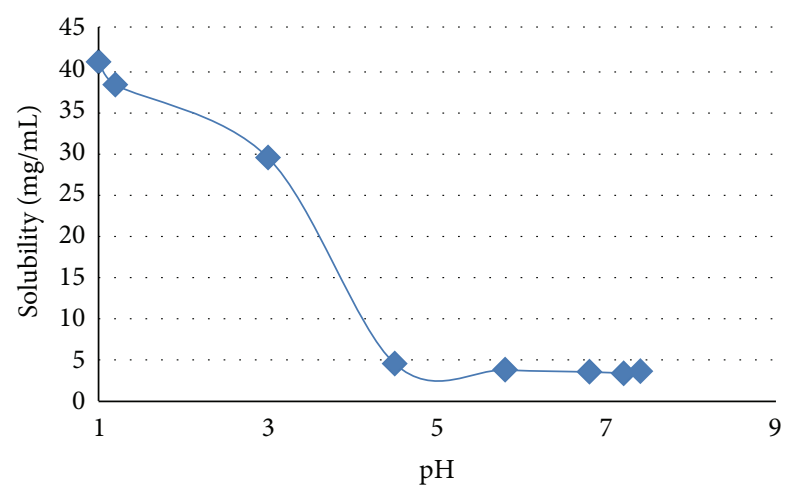

FIGURE 2: Graphical representation of ofloxacin solubility study curve at different $\mathrm{pH}$ range at room temperature.

$3.79 \mathrm{mg} / \mathrm{mL}, 3.55 \mathrm{mg} / \mathrm{mL}, 3.39 \mathrm{mg} / \mathrm{mL}$, and $3.24 \mathrm{mg} / \mathrm{mL}$ in media with pH 1, pH 1.2, $\mathrm{pH} 3, \mathrm{pH} 4.5, \mathrm{pH} 5.8, \mathrm{pH} 6.8, \mathrm{pH}$ 7.2 , and $\mathrm{pH} 7.4$, respectively.

3.2. Evaluation of Coating Thickness. The thickness measurement was performed to check uniform deposition of enteric coat on capsule shell body because it is necessary for the capsule to stay intact in acidic media for entire duration of residence in stomach. Initially, the bare capsule showed the thickness of $0.1104 \pm 0.0016 \mathrm{~mm}$, while after coating, the thickness appeared to be $0.1747 \pm 0.0058 \mathrm{~mm}$. Hence, the coating attained by the capsule shell was evaluated to be $0.0643 \mathrm{~mm}$.

3.3. Buoyancy Time for the Various Formulations. Buoyancy of formulation depends on the type and concentration of excipients used. The formulations with HPMC grades showed better floating time while Carbopol 940 provided reduced floating property as negative effect on floating behavior of delivery system. This was previously suggested by $\mathrm{Li}$ et al. by moisture absorption isotherm of Carbopol 934P, HPMC K4M, and K100LV. The moisture gain for Carbopol 934P was significantly higher compared with HPMC K4M and K100LV (55\% weight gain for Carbopol 934P versus 33\% for HPMC $\mathrm{K} 4 \mathrm{M}$ and $\mathrm{K} 100 \mathrm{LV}$ at $\mathrm{RH}$ of $95 \%$ ). This results in a dramatic increase in the density of the GFDDS which, in turn, shows a corresponding decrease in the floating capacity of floating delivery devices. Xanthan gum depicted satisfactory floating property when used in higher concentration $(60 \mathrm{mg})$.

Table 3 reveals that floating property of formulation containing Carbopol 940 and Xanthan gum increases with an increase in polymer concentration. The formulations $\mathrm{F}_{\mathrm{Al}}$, $\mathrm{F}_{\mathrm{A} 2}, \mathrm{~F}_{\mathrm{E} 1}, \mathrm{~F}_{\mathrm{E} 2}, \mathrm{~F}_{\mathrm{K} 1}, \mathrm{~F}_{\mathrm{K} 2}, \mathrm{~F}_{\mathrm{G} 1}, \mathrm{~F}_{\mathrm{G} 2}$, and $\mathrm{F}_{\mathrm{X} 1}$ showed desired floating time for more than $9 \mathrm{hrs}$ and seemed to be developed formulations.

3.4. In Vitro Drug Release. The sustained release polymers used in formulation on contact with aqueous media get hydrated forming gel matrix that entrapped the air responsible for buoyancy. This gel structure acts as a reservoir system for sustained drug release which is governed by slow diffusion through hydrated gel barrier [19, 20]. Figure 4 represents comparative release of ofloxacin from various formulations containing different sustained release polymers. The effective sustained release was obtained from all formulations. The formulations $\mathrm{F}_{\mathrm{G} 1}, \mathrm{~F}_{\mathrm{G} 2}, \mathrm{~F}_{\mathrm{K} 1}, \mathrm{~F}_{\mathrm{K} 2}$, and $\mathrm{F}_{\mathrm{C} 1}$ showed much sustained drug release $35.01 \%, 52.01 \%, 31.66 \%, 54.52 \%$, and $73.47 \%$, respectively in 9 hours. The formulations $\mathrm{F}_{\mathrm{E} 1}, \mathrm{~F}_{\mathrm{E} 2}$, $\mathrm{F}_{\mathrm{X} 1}$, and $\mathrm{F}_{\mathrm{C} 2}$ successfully sustained the drug release till 9 hours and depicted the drug release as $88.08 \%$, 99.08\%, $89.70 \%$, and $98.65 \%$, respectively. Formulations $\mathrm{F}_{\mathrm{A} 1}, \mathrm{~F}_{\mathrm{A} 2}$, and $\mathrm{F}_{\mathrm{X} 2}$ showed the complete drug release within 6,7 , and 8 hours, respectively. The formulations $\mathrm{F}_{\mathrm{E} 2}$ and $\mathrm{F}_{\mathrm{A} 2}$ were able to sustain the drug release up to $9 \mathrm{hrs}$ with considerably higher drug release $98.65 \%$ and $99.08 \%$ respectively, and proved to be developed batches.

3.5. Release Kinetics. Release behavior of prepared formulations was essentially studied by various mathematical models. Equation (2) describes zero order kinetics, where the drug release rate in a system is independent of its concentration [21] and ideal to describe coated dosage forms or membrane controlled dosage form [22]. The first-order Equation (3) describes the release from system where release rate is concentration dependent $[23,24]$; it described the release of drugs from insoluble matrix as a square root of timedependent process based on Fickian diffusion equation (4). Korsmeyer-Peppas equation (5) suggests the drug release from swellable polymer $[25,26]$. The Hixson-Crowell cube root law Equation (5) describes the release from systems where there is a change in surface area and diameter of particles or tablets.

$$
\begin{gathered}
Q_{t}=k_{0} t, \\
\log Q_{t}=\log Q_{0}-k_{1} t, \\
Q_{t}=k_{\mathrm{H}} t^{1 / 2}, \\
\frac{M_{t}}{M_{0}}=k_{\mathrm{KP}} t^{n}, \\
Q_{0}^{1 / 3}-Q_{t}^{1 / 3}=k_{\mathrm{HC}} t,
\end{gathered}
$$

where $Q_{t}$ is the amount of drug released at time, $Q_{0}$ is the initial amount of the drug in the formulation and $k_{0}, k_{1}, k_{\mathrm{H}}$, $k_{\mathrm{KP}}$, and $k_{\mathrm{HC}}$ are the release rate constants for zero order, first-order, Higuchi model, Korsmeyer-Peppas model and Hixson-Crowell model, respectively. In (6), $M_{t}$ and $M_{0}$ are the amount of drug released at time $t$ and time 0 while $n$ is the diffusional coefficient.

The graphs for each formulation plotted according to the above equations were used to calculate correlation factors $\left(r^{2}\right)$ and release exponents $(n)$. All formulations suggested the Korsmeyer-Peppas as best fit model except $\mathrm{F}_{\mathrm{E} 2}$ and $\mathrm{F}_{\mathrm{X} 2}$ where drug release was in concordance with Higuchi model. As the fabricated capsule is exposed only from single planar side where there is absence of edge effect on dissolution media, it would behave as polymeric film like geometry for drug delivery in diffusion study of different release exponent. The $n$ value $0.5<n<1.0$ indicates an anomalous drug transport. 


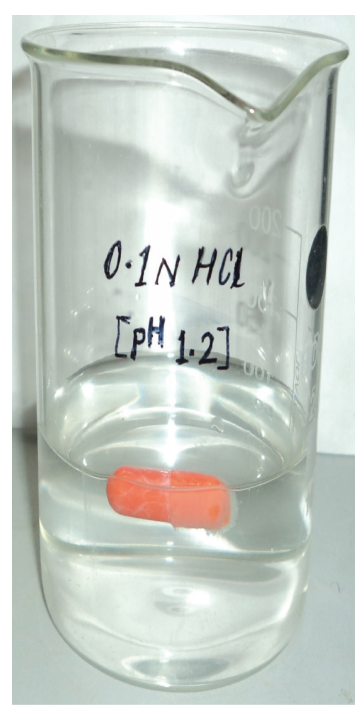

(a)

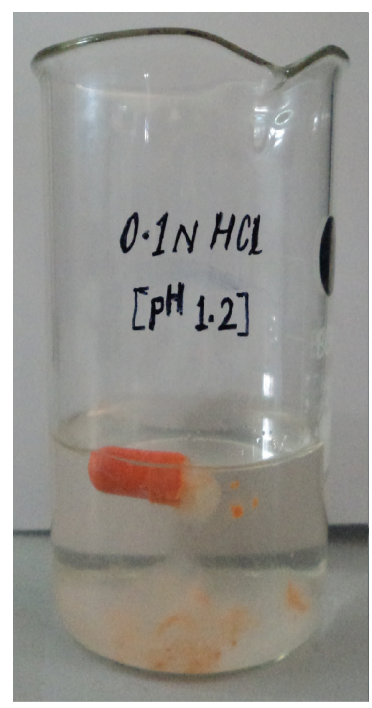

(b)

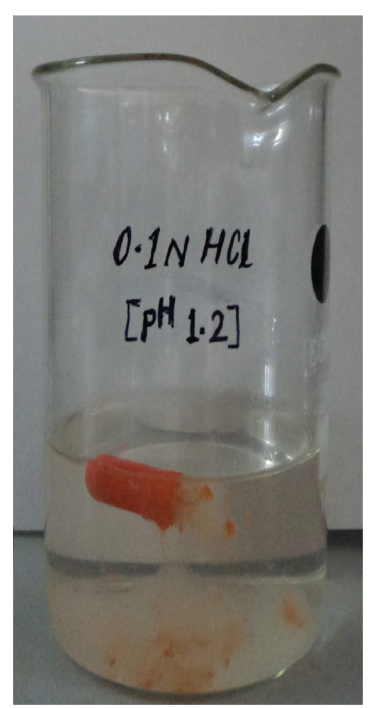

(c)

FIGURE 3: Floating behavior of NDCC in acidic buffer $\mathrm{pH}$ 1.2. The figure demonstrates the floating behavior of developed formulation $\mathrm{F}_{\mathrm{E} 2}$ : (a) $0 \mathrm{hr}$, (b) $5 \mathrm{hrs}$, and (c) $9 \mathrm{hrs}$.

TABLE 3: In vitro floating study of various formulations.

\begin{tabular}{lcc}
\hline Formulation & $\begin{array}{c}\text { Buoyancy time } \\
\text { (Yang et al. }\end{array}$ & $\begin{array}{c}\text { Buoyancy time } \\
\text { (Rosa et al. })\end{array}$ \\
\hline $\mathrm{F}_{\mathrm{A} 1}$ & $>9 \mathrm{hrs}$ & $>9 \mathrm{hrs}$ \\
$\mathrm{F}_{\mathrm{A} 2}$ & $>9 \mathrm{hrs}$ & $>9 \mathrm{hrs}$ \\
$\mathrm{F}_{\mathrm{E} 1}$ & $>9 \mathrm{hrs}$ & $>9 \mathrm{hrs}$ \\
$\mathrm{F}_{\mathrm{E} 2}$ & $>9 \mathrm{hrs}$ & $>9 \mathrm{hrs}$ \\
$\mathrm{F}_{\mathrm{K} 1}$ & $>9 \mathrm{hrs}$ & $>9 \mathrm{hrs}$ \\
$\mathrm{F}_{\mathrm{K} 2}$ & $>9 \mathrm{hrs}$ & $>9 \mathrm{hrs}$ \\
$\mathrm{F}_{\mathrm{C} 1}$ & $>4 \mathrm{hrs}$ & $>5 \mathrm{hrs}$ \\
$\mathrm{F}_{\mathrm{C} 2}$ & $>4 \mathrm{hrs}$ \\
$\mathrm{F}_{\mathrm{G} 1}$ & $>9 \mathrm{hrs} \mathrm{hrs}$ \\
$\mathrm{F}_{\mathrm{G} 2}$ & $>9 \mathrm{hrs}$ & $>9 \mathrm{hrs}$ \\
$\mathrm{F}_{\mathrm{X} 1}$ & $>9 \mathrm{hrs}$ & $>9 \mathrm{hrs}$ \\
$\mathrm{F}_{\mathrm{X} 2}$ & $>7 \mathrm{hrs}$ & $>9 \mathrm{hrs}$ \\
\hline
\end{tabular}

The release exponent of 0.5 can serve as an indication for diffusion controlled drug release $[27,28]$.

3.6. Stability Testing. Intention behind stability study of drug and polymer was to yield evidence regarding the quality of formulation which varies with time under the influence of various environmental factors such as temperature and humidity. The samples tested for drug release and infrared spectroscopy after the specified time proved that the formulation remained stable and absence of drug polymer interaction. The in vitro drug release from formulations subjected to stress condition was quite similar to that of initial formulations. Also, peaks observed in infrared spectroscopy of pure ofloxacin, $C=0$ stretching vibration $1750-1700 \mathrm{~cm}^{-1}$ and $\mathrm{O}-\mathrm{H}$ stretching at $3050-3000 \mathrm{~cm}^{-1}$ remained unchanged in

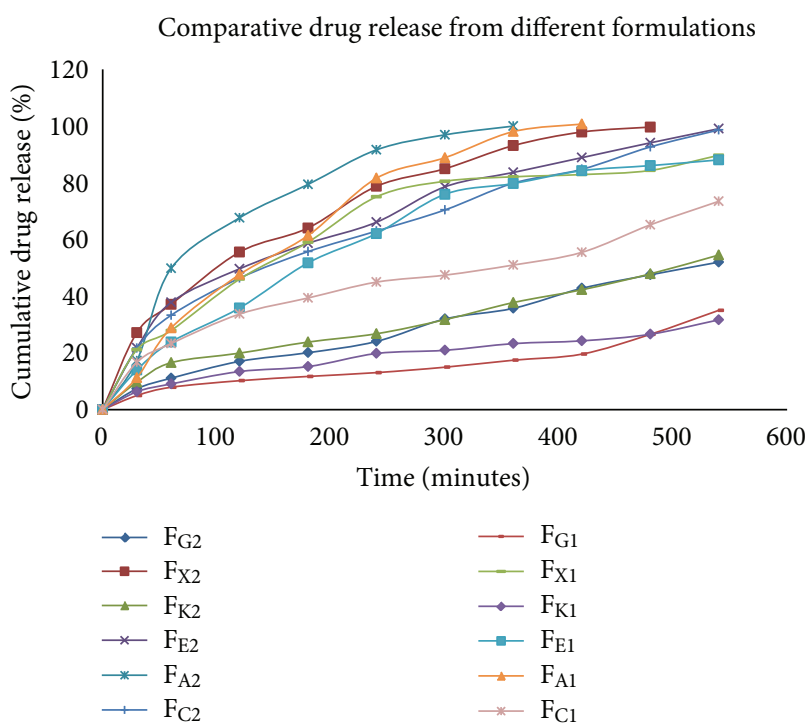

FIGURE 4: In vitro drug release of Ofloxacin using different polymers.

drug polymer mixture subjected to stability study indicating compatibility of ofloxacin with used polymers.

\section{Discussion}

4.1. Solubility Study of Ofloxacin at Different $p H$. The solubility of ofloxacin varied significantly with the change in $\mathrm{pH}$ of the media. In acidic media the solubility was found to be much higher compared to neutral and alkaline media. The solubility was highest $(41.2 \mathrm{mg} / \mathrm{mL})$ in $\mathrm{pH} 1$ media which considerably decreased with increase in $\mathrm{pH}$ of solvent. The solubility drastically reduced to $29.4 \mathrm{mg} / \mathrm{mL}$ when the $\mathrm{pH}$ 3 media was used. Also, in neutral and alkaline media the 
TABLE 4: Mathematical models for different formulations.

\begin{tabular}{|c|c|c|c|c|c|c|c|}
\hline \multirow{2}{*}{ Formulation code } & \multicolumn{5}{|c|}{ Correlation coefficient $\left(r^{2}\right)$} & \multirow{2}{*}{ Release exponent $(n)$} & \multirow{2}{*}{ Best fit model } \\
\hline & Zero order & First order & Higuchi & Korsmeyer-Peppas & Hixson-Crowell & & \\
\hline $\mathrm{F}_{\mathrm{A} 1}$ & 0.947 & 0.924 & 0.975 & 0.993 & 0.690 & 0.8086 & Korsmeyer-Peppas \\
\hline $\mathrm{F}_{\mathrm{A} 2}$ & 0.857 & 0.973 & 0.965 & 0.977 & 0.587 & 0.6494 & Korsmeyer-Peppas \\
\hline $\mathrm{F}_{\mathrm{E} 1}$ & 0.917 & 0.988 & 0.979 & 0.994 & 0.642 & 0.6593 & Korsmeyer-Peppas \\
\hline $\mathrm{F}_{\mathrm{E} 2}$ & 0.909 & 0.875 & 0.995 & 0.971 & 0.566 & 0.4996 & Higuchi \\
\hline $\mathrm{F}_{\mathrm{K} 1}$ & 0.943 & 0.959 & 0.986 & 0.998 & 0.607 & 0.5318 & Korsmeyer-Peppas \\
\hline $\mathrm{F}_{\mathrm{K} 2}$ & 0.970 & 0.974 & 0.962 & 0.990 & 0.645 & 0.5511 & Korsmeyer-Peppas \\
\hline $\mathrm{F}_{\mathrm{C} 1}$ & 0.929 & 0.951 & 0.949 & 0.977 & 0.949 & 0.4786 & Korsmeyer-Peppas \\
\hline $\mathrm{F}_{\mathrm{C} 2}$ & 0.935 & 0.853 & 0.965 & 0.975 & 0.965 & 0.5089 & Korsmeyer-Peppas \\
\hline $\mathrm{F}_{\mathrm{G} 1}$ & 0.919 & 0.893 & 0.850 & 0.968 & 0.684 & 0.5764 & Korsmeyer-Peppas \\
\hline $\mathrm{F}_{\mathrm{G} 2}$ & 0.990 & 0.988 & 0.953 & 0.993 & 0.717 & 0.6751 & Korsmeyer-Peppas \\
\hline $\mathrm{F}_{\mathrm{X} 1}$ & 0.847 & 0.957 & 0.965 & 0.975 & 0.559 & 0.5291 & Korsmeyer-Peppas \\
\hline $\mathrm{F}_{\mathrm{X} 2}$ & 0.897 & 0.892 & 0.994 & 0.967 & 0.560 & 0.4870 & Higuchi \\
\hline
\end{tabular}

solubility remained less than $4 \mathrm{mg} / \mathrm{mL}$. The bioavailability of drug with higher dose gets affected by this $\mathrm{pH}$ dependent solubility condition.

4.2. Evaluation of Coating Thickness. The efficient thickness was achieved on capsule by Eudragit S100 coating. The thickness was sufficient to resist the deformation in acidic media for more than 2 hrs. From the results obtained by measurement of coating thickness, it can be assumed that there will not be any deformation of capsule body in vivo due to less deviation found in study; it indicates uniform deposition of enteric coat. It was also confirmed by visual observation of intactness of capsule shell in simulated gastric fluid (SGF) in vitro for more than $9 \mathrm{hrs}$.

4.3. In Vitro Buoyancy Studies. The formulations comprising of different grades of $\operatorname{HPMC}\left(\mathrm{F}_{\mathrm{A} 1}, \mathrm{~F}_{\mathrm{A} 2}, \mathrm{~F}_{\mathrm{E} 1}, \mathrm{~F}_{\mathrm{E} 2}, \mathrm{~F}_{\mathrm{K} 1}\right.$, and $\left.\mathrm{F}_{\mathrm{K} 2}\right)$ and Guar gum $\left(\mathrm{F}_{\mathrm{G} 1}\right.$ and $\left.\mathrm{F}_{\mathrm{G} 2}\right)$ provided better floating property. These formulations showed floating time for more than 9 hrs. As Carbopol has negative effect on floating, formulations $\mathrm{F}_{\mathrm{C} 1}$ and $\mathrm{F}_{\mathrm{C} 2}$ failed to maintain the buoyancy for desired span. Formulations with Xanthan gum also exhibited the good buoyancy of capsules. However, the formulation $\mathrm{F}_{\mathrm{X} 2}$ failed to maintain buoyancy for 9 hrs where the concentration of Xanthan gum was lesser (40 mg).

4.4. In Vitro Drug Release. All the prepared formulations were able to control the release of the drug efficiently over the span of 9 hours, except the formulations $\mathrm{F}_{\mathrm{A} 1}, \mathrm{~F}_{\mathrm{A} 2}$, and $\mathrm{F}_{\mathrm{X} 2}$ which showed total drug release within 7,8 , and 9 hours, respectively. Drug release was undesirably much sustained from formulations $\mathrm{F}_{\mathrm{G} 1}, \mathrm{~F}_{\mathrm{G} 2}, \mathrm{~F}_{\mathrm{K} 1}, \mathrm{~F}_{\mathrm{K} 2}$, and $\mathrm{F}_{\mathrm{C} 1}$ which remained less than $50 \%$ till $9 \mathrm{hrs}$. The formulations comprising of HPMC polymers showed better results. However, $\mathrm{F}_{\mathrm{Al}}$ and $\mathrm{F}_{\mathrm{A} 2}$ containing HPMC A failed to sustain the release up to $9 \mathrm{hrs}$. Formulations $\mathrm{F}_{\mathrm{E} 2}$ and $\mathrm{F}_{\mathrm{C} 2}$ produced the better results by providing maximum drug release in sustained manner till 9 hrs. Hence, it indicates that when HPMC E and Carbopol 940 were used in concentration of $40 \mathrm{mg}$, they exhibited desired outcome, as formulation $\mathrm{F}_{\mathrm{C} 2}$ has poor floating property which leads to unfavorable batch. Thus, $\mathrm{F}_{\mathrm{E} 2}$ turned out to be best developed formulation where $40 \mathrm{mg}$ HPMC E15 was taken into account.

4.5. Drug Release Kinetics. All the formulations except $\mathrm{F}_{\mathrm{E} 2}$ and $\mathrm{F}_{\mathrm{X} 2}$ followed the Korsmeyer-Peppas model for drug release indicating the drug release from swellable polymers. The release exponent suggests the drug release mechanisms from polymeric controlled delivery systems. KorsmeyerPeppas model was found to be best fitted with anomalous diffusion for all the formulations with $n$ values between 0.5 and 1 except for formulation $\mathrm{F}_{\mathrm{E} 2}$ and $\mathrm{F}_{\mathrm{X} 2}$, where they followed Higuchi model and diffusion-controlled drug release mechanism. The developed formulation $\mathrm{F}_{\mathrm{E} 2}$ depicted the drug release according to Korsmeyer-Peppas model as shown in Table 4.

4.6. Stability Studies. Stability study of formulations was investigated successfully indicating that formulation subjected to stress remained stable after 3 months. The drug release behavior remained similar to the unsubjected formulations. Also, FT-IR spectroscopy data reported no interaction between drug and polymers

\section{Conclusion}

The present study suggests that the use of NDCC for oral delivery of Ofloxacin could be an alternative to improve its systemic availability which could be regulated by the floating approach. As Ofloxacin efficiently absorbed from stomach, bioavailability of Ofloxacin could be considerably increased by gastroretentive NDCC. This study shows the release behavior and buoyancy of formulations by using various sustained release polymers. The release behavior of developed formulation $\mathrm{F}_{\mathrm{E} 2}$ showed release kinetics according to Korsmeyer-Peppas model indicating drug release from swellable polymer. Also, the floating behavior of formulations with Guar gum and HPMC grade polymers was satisfactory. 
The designed dosage system can have futuristic applications over payloads which require stomach-specific delivery.

\section{References}

[1] S. Hwang, H. Park, and K. Park, "Gastric retentive drug-delivery systems," Critical Reviews in Therapeutic Drug Carrier Systems, vol. 15, no. 3, pp. 243-284, 1998.

[2] A. A. Deshpande, C. T. Rhodes, N. H. Shah, and A. W. Malick, "Controlled-release drug delivery systems for prolonged gastric residence: an overview," Drug Development and Industrial Pharmacy, vol. 22, no. 6, pp. 531-539, 1996.

[3] S. Arora, J. Ali, A. Ahuja, R. K. Khar, and S. Baboota, "Floating drug delivery systems: a review," AAPS PharmSciTech, vol. 6, no. 3, article 47, pp. 372-390, 2005.

[4] B. N. Singh and K. H. Kim, "Floating drug delivery systems: an approach to oral controlled drug delivery via gastric retention," Journal of Controlled Release, vol. 63, no. 3, pp. 235-259, 2000.

[5] R. Khosla and S. S. Davis, "The effect of tablet size on the gastric emptying of non-disintegrating tablets," International Journal of Pharmaceutics, vol. 62, no. 2-3, pp. R9-R11, 1990.

[6] S. Davis, A. F. Stockwell, and M. J. Taylor, "The effect of density on gastric emptying of single and multiple unit dosage forms," Pharmaceutical Research, vol. 3, no. 4, pp. 208-213, 1986.

[7] P. Mojaverian, P. H. Vlasses, P. E. Kellner, and M. L. Rocci, "Effects of gender, posture, and age on gastric residence time of an indigestible solid: pharmaceutical considerations," Pharmaceutical Research, vol. 5, no. 10, pp. 639-644, 1988.

[8] N. Rouge, E. Allémann, M. Gex-Fabry et al., "Comparative pharmacokinetic study of a floating multiple-unit capsule, a high-density multiple-unit capsule and an immediate-release tablet containing $25 \mathrm{mg}$ atenolol," Pharmaceutica Acta Helvetiae, vol. 73, no. 2, pp. 81-87, 1998.

[9] R. N. Chen, H. O. Ho, C. Y. Yu, and M. T. Sheu, "Development of swelling/floating gastroretentive drug delivery system based on a combination of hydroxyethyl cellulose and sodium carboxymethyl cellulose for Losartan and its clinical relevance in healthy volunteers with CYP2C9 polymorphism," European Journal of Pharmaceutical Sciences, vol. 39, no. 1-3, pp. 82-89, 2010.

[10] Y. Liu, J. Zhang, Y. Gao, and J. Zhu, "Preparation and evaluation of glyceryl monooleate-coated hollow-bioadhesive microspheres for gastroretentive drug delivery," International Journal of Pharmaceutics, vol. 413, no. 1-2, pp. 103-109, 2011.

[11] R. Gröning, M. Berntgen, and M. Georgarakis, "Acyclovir serum concentrations following peroral administration of magnetic depot tablets and the influence of extracorporal magnets to control gastrointestinal transit," European Journal of Pharmaceutics and Biopharmaceutics, vol. 46, no. 3, pp. 285-291, 1998.

[12] L. Whitehead, J. T. Fell, J. H. Collett, H. L. Sharma, and A. M. Smith, "Floating dosage forms: an in vivo study demonstrating prolonged gastric retention," Journal of Controlled Release, vol. 55, no. 1, pp. 3-12, 1998.

[13] M. D. Chavanpatil, P. Jain, S. Chaudhari, R. Shear, and P. R. Vavia, "Novel sustained release, swellable and bioadhesive gastroretentive drug delivery system for ofloxacin," International Journal of Pharmaceutics, vol. 316, no. 1-2, pp. 86-92, 2006.

[14] B. Castro, P. Gameiro, J. L. F. C. Lima, C. Matos, and S. Reis, "Interaction of drug with hexadecylphocholine micelles. Derivative spectroscopy, acid-base and solubility studies," Materials Science and Engineering: C, vol. 18, no. 1-2, pp. 71-78, 2001.
[15] A. Mehta et al., "Evaluation of fluid-bed process for enteric coating systems," Pharmaceutical Technology, vol. 10, no. 4, pp. 46-56, 1986.

[16] S. Li, K. M. Feld, and C. R. Kowarski, "Preparation and evaluation of Eudragit acrylic resin for controlled drug release of pseudoephedrine hydrochloride," Drug Development and Industrial Pharmacy, vol. 17, no. 12, pp. 1655-1683, 1991.

[17] L. Yang, J. Eshraghi, and R. Fassihi, "A new intragastric delivery system for the treatment of Helicobacter pylori associated gastric ulcer: in vitro evaluation," Journal of Controlled Release, vol. 57, no. 3, pp. 215-222, 1999.

[18] B. R. Matthews, "Regulatory aspects of stability testing in Europe," Drug Development and Industrial Pharmacy, vol. 25, no. 7, pp. 831-856, 1999.

[19] H. E. Huber, L. B. Dale, and G. L. Christenson, "Utilization of hydrophilic gums for the control of drug release from tablet formulations. I. Disintegration and dissolution behavior," Journal of Pharmaceutical Sciences, vol. 55, no. 9, pp. 974-976, 1966.

[20] P. R. Sheth and J. Tossounian, "The hydrodynamically balanced system (HBS(TM)): a novel drug delivery system for oral use," Drug Development and Industrial Pharmacy, vol. 10, no. 2, pp. 313-339, 1984.

[21] T. Hadjiioannou, G. D. Christian, M. A. Koupparis, and P. E. Macheras, Quantitative Calculations in Pharmaceutical Practice and Research, VCH Publishers, New York, NY, USA, 1993.

[22] F. Ocak and I. Ağabeyoğlu, "Development of a membranecontrolled transdermal therapeutic system containing isosorbide dinitrate," International Journal of Pharmaceutics, vol. 180, no. 2, pp. 177-183, 1999.

[23] D. Bourne, Modern Pharmaceutics, Marcel Dekker Inc., New York, NY, USA, 2002.

[24] T. Higuchi, "Mechanism of sustained-action medication. Theoretical analysis of rate of release of solid drugs dispersed in solid matrices," Journal of Pharmaceutical Sciences, vol. 52, no. 12, pp. 1145-1149, 1963.

[25] R. W. Korsmeyer, S. R. Lustig, and N. A. Peppas, "Solute and penetrant diffusion in swellable polymers. I. Mathematical modeling," Journal of Polymer Science: Polymer Physics Edition, vol. 24, no. 2, pp. 395-408, 1986.

[26] R. W. Korsmeyer, E. Von Meerwall, and N. A. Peppas, "Solute and penetrant diffusion in swellable polymers. II. Verification of theoretical models," Journal of Polymer Science: Polymer Physics Edition, vol. 24, no. 2, pp. 409-434, 1986.

[27] P. L. Ritger and N. A. Peppas, "A simple equation for desciption of solute release I. Fickian and non-Fickian release from nonswellable devices in the form of slabs, spheres, cylinders or discs," Journal of Controlled Release, vol. 5, no. 1, pp. 23-36, 1987.

[28] P. L. Ritger and N. A. Peppas, "A simple equation for description of solute release II. Fickian and anomalous release from swellable devices," Journal of Controlled Release, vol. 5, no. 1, pp. 37-42, 1987. 

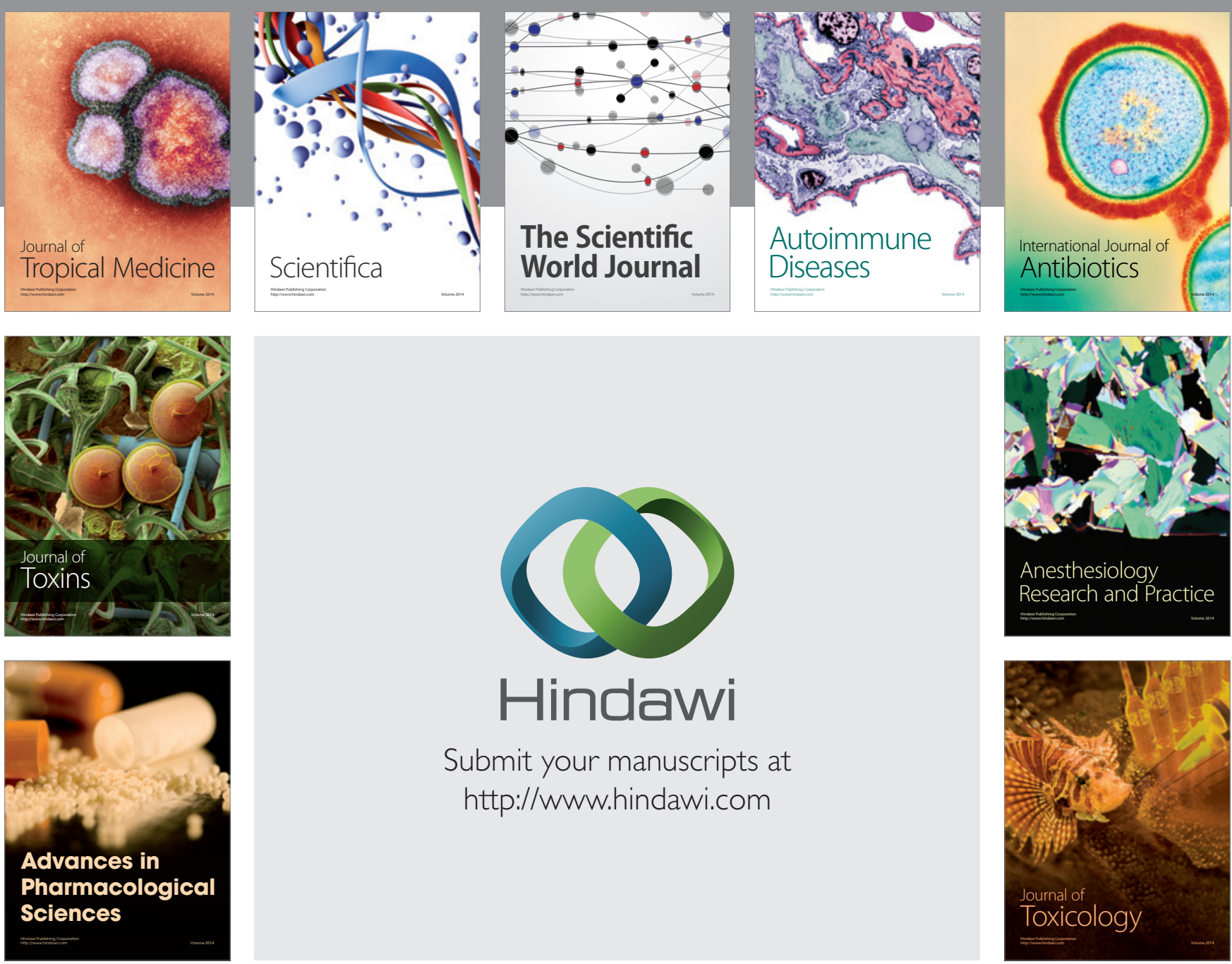

\section{Hindawi}

Submit your manuscripts at

http://www.hindawi.com
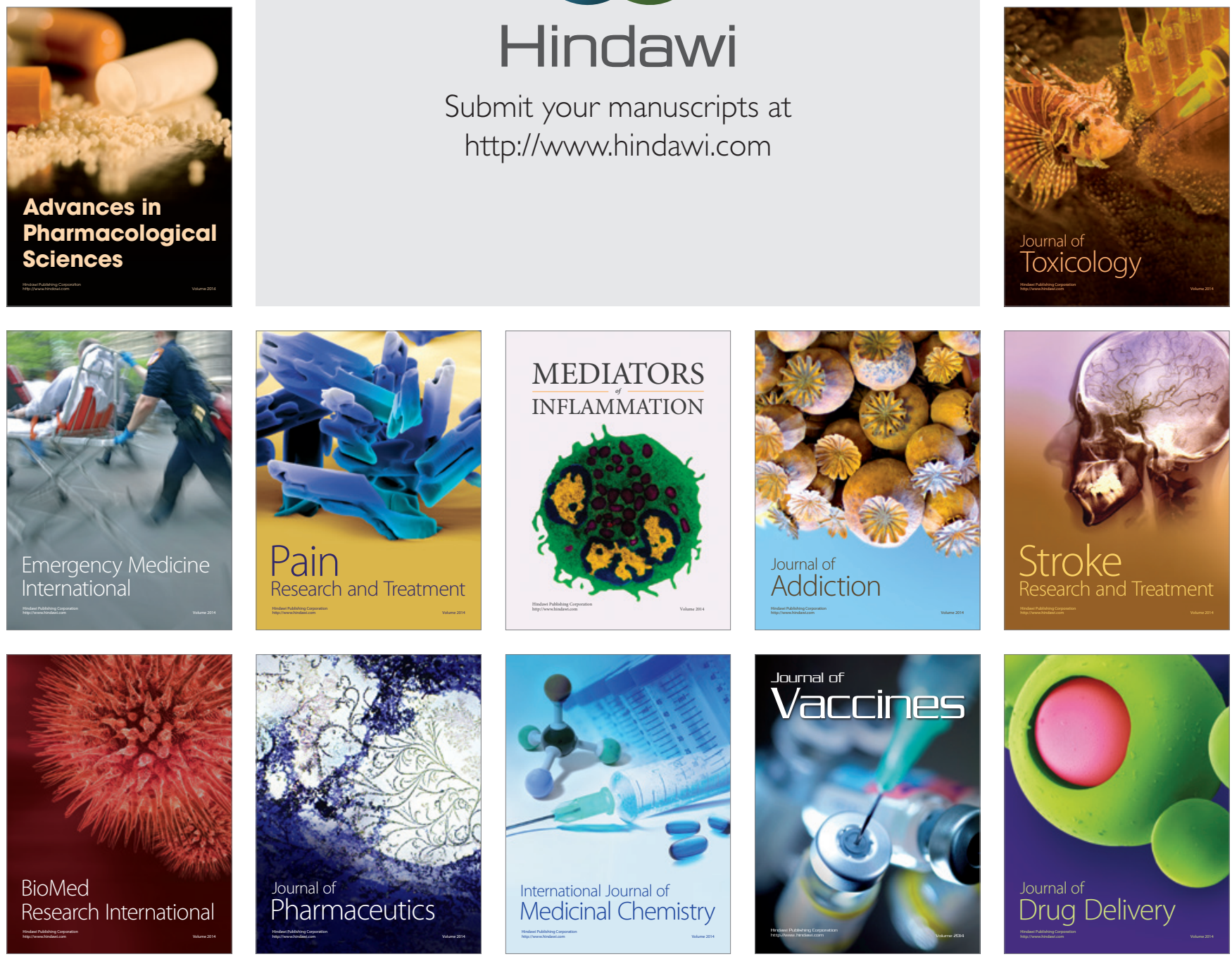